\title{
Percepción de los afrodescendientes e indígenas sobre inclusión y racismo en la televisión ecuatoriana
}

\section{Perception of Afro-descendants and indigenous people about inclusion and racism on Ecuadorian television}

\author{
Ingrid Viviana Estrella Tutivén ${ }^{1}$ \\ ${ }^{1}$ Universidad de Guayaquil, Ecuador \\ *iestrella2010@hotmail.com
}

DOI: https://doi.org/10.26871/killkanasocial.v4i2.193

\begin{abstract}
Resumen
Este trabajo tiene como objetivo elaborar una propuesta comunicativa que contribuya a mejorar los comportamientos de la televisión nacional, respecto al tema de la inclusión e igualdad social, se tratará de analizar cómo la Ley Orgánica de Comunicación intenta que los mass media respeten los derechos de las minorías raciales conculcados por siglos. La investigación además aporta con la educación de las comunidades afroecuatorianas e indígenas, comunidades a las que va dirigida. Esta propuesta lo que ofrece es la inclusión de estas razas en espacios televisivos sin fomentar la discriminación ni el racismo y trata de buscar la unión de etnias y enseñar los sucesos del proceso de inclusión en la nación. A lo largo del estudio de este proyecto de titulación, el lector reconocerá de qué manera ha sido incluido gradualmente el afroecuatoriano y el indígena en el país, y cómo se forjó la historia de los comunicadores, periodistas o reporteros afros e indígenas en otras partes del mundo. Para realizar el presente estudio se tomó una muestra no probabilística por conveniencia compuesta por 15 personas indígenas, que trabajan en mercados de la ciudad de Guayaquil; y, 15 personas afrodescendientes, que viven en Guayaquil, por diferentes motivos. Ellos fueron encuestados con el fin de saber si perciben que en la televisión ecuatoriana discriminan a las personas de sus razas. Además, se les preguntó si la Ley Orgánica de Comunicación ha contribuido para que esta discriminación vaya disminuyendo progresivamente. Sus respuestas son valiosas aportaciones en la lucha contra la marginación social que sufren indígenas y afrodescendientes en el Ecuador.
\end{abstract}

Palabras clave: Comunidades afroecuatorianas, Comunidades indígenas, Igualdad social, Inclusión .

\begin{abstract}
This research aims to elaborate a communicative proposal that contributes to improving the behavior of national television, regarding the issue of inclusion and social equality. It will try to motivate young people and even entire communities that seek a public space, to defend the rights not respected for centuries and also contribute with the education of afroecuadorian and indigenous communities, communities to which this research is directed. This proposal offers the inclusion of these races in television spaces without promoting discrimination or racism and seeks to seek the union of ethnicities and teach the events of the process of inclusion in the nation. Throughout the study of this titling project, the reader will recognize how afro-ecuadorian and indigenous have gradually been included in the country, and how was forged the history of afro and indian communicators, journalists or reporters in other parts of the world. In order to carry out the present study, we took a non-probabilistic convenience sample composed of 15 indigenous people, who work in markets in the city of Guayaquil; and, 15 people of African descent, who live in Guayaquil, for different reasons. They were surveyed in order to know if they perceive that in Ecuadorian television they discriminate against people of their races. In addition, they were asked if the Organic Law of Communication has contributed to the progressive reduction of this discrimination. Their responses are valuable contributions in the fight against the social marginalization suffered by indigenous people and people of African descent in Ecuador.
\end{abstract}

Keywords: Afro-Ecuadorian communities, Indigenous communities, Social equality, Inclusion.

\section{Introducción}

Los periodistas afrodescendientes e indígenas han tenido poca cabida en la televisión del Ecuador, desde sus inicios. Aún más, si se contabilizan a los que trabajan actualmente en los canales, el número sería muy reducido, en comparación del resto de comunicadores, que son en su mayoría de raza blanca y mestiza, en ese orden.

Cuando la televisión comenzó a desarrollarse y de a poco surgieron las producciones nacionales, con el pretexto de reconocer los derechos de la comunidad afro se daban 
papeles actorales a gente de raza negra, pero eran roles estereotipados en los que tenían que actuar de mendigos, ladrones, sirvientes y muchas veces les tocaba rememorar en carne propia el papel de esclavos siendo esta la única oportunidad en la que un afroecuatoriano podía salir en la pantalla chica. Esto fomentaba la utilización de los clichés culturales negativos que siempre han imperado en nuestra sociedad.

El propósito de este trabajo no es polemizar ni tampoco esconder la realidad, es un trabajo hecho para que, los que no saben, conozcan y quienes no oyeron, oigan, que todo ser humano tiene los mismos derechos, derechos inalienables e imborrables que nos hacen parte de la historia y cultura de una nación.

En este trabajo trato de sintetizar las opiniones de muchos actores y periodistas de las razas negra e indígena, a los que se les ha hecho muy difícil entrar al mundo de la televisión, por el hecho de ser de un tono o color de piel diferente al blanco.

\section{Marco teórico o antecedentes}

Puede definirse la discriminación como el trato desigual, en cuanto a prerrogativas, consideración social, derechos, etc., que se establece entre individuos pertenecientes a grupos raciales distintos, en aquellos países o regiones donde uno es predominante. Y por prejuicio se entiende que es la acción y efecto de prejuzgar, es decir, de juzgar las cosas antes del tiempo oportuno o sin tener de ellas cabal conocimiento.

La Declaración Universal de los Derechos Humanos, aprobada por la Asamblea General de las Naciones Unidas en 1948, contiene una amplia definición de los derechos humanos, aunque carece de efecto vinculante sobre los Estados miembros. Posteriormente la Asamblea General aprobó el Acuerdo sobre Derechos Civiles y Políticos (que entró en vigor en 1976), así como acuerdos específicos sobre prevención y penalización del genocidio y sobre eliminación de cualquier forma de discriminación racial (ONU, 1948).

El Ecuador nació hace 177 años, se fundó bajo los indicios de la discriminación y el racismo y en su carta fundacional otorgo la exclusión de los pueblos indígenas y negros.

Si bien es cierto que, gracias a la constancia de la lucha indígena, recién desde el año1998 los derechos como pueblos indígenas fueron consignados en la Carta Política, y se ratificó el Convenio 169 de la OIT, sin embargo, éstos en la práctica fueron letra caída y durante muchos años no hubo avance en cuanto garantizar sus súplicas históricas a territorio, independencia, libertad, respeto y desarrollo de sus culturas milenarias.

La discriminación, el racismo y sus formas de intolerancia son un problema ético, moral y jurídico, pero también obstáculos para el progreso cultual, social y económico de nuestro país y el ejercicio de una auténtica liberalismo.
En la sociedad es fundamental la comunicación, y mejor aún si es en una forma respetuosa. Los derechos humanos promueven y exigen este derecho de igualdad en la calidad de emisores, receptores y actores de la comunicación.

Personas indígenas, montubias, afrodescendientes, mujeres etc., han sufrido afectación mediática negativa, de manera directa o indirecta. Estos estereotipos culturales no han cesado en su totalidad, hecho que podría manifestarse en múltiples formas.

Son los medios audiovisuales, por su propia naturaleza, donde el fenómeno de la discriminación y su antónimo, la inclusión, resultan más evidentes.

Por ejemplo, en las comedias o telenovelas ecuatorianas, se podía observar los comerciales con hombres y mujeres, blancos caucásicos, pero casi nunca una persona de raza negra o indígena.

Son muchas las evidencias de las prácticas del racismo. La revista Vistazo en su edición 858 de mayo de 2003 encuestó sobre el grado de aceptación racial en Quito y Guayaquil, arrojando datos que no sorprenden: Los blancos - apenas el $10.46 \%$ de todos los ecuatorianos según censo del 2001- gozan de un $93.3 \%$ de aceptación social y "son la minoría a la que muchos quisieran pertenecer", mientras que los mestizos - quienes en el país son el $77 \%$ - solo son aceptados el $3.75 \%$, frente al $1.67 \%$ de los afros y el $1.25 \%$ de los indígenas.

De la misma manera, la encuesta de Vistazo revela que los blancos en Ecuador tienen el $85 \%$ de posibilidades para conseguir un empleo, por encima de los mestizos que solo tienen el $8.75 \%$ de obtenerlo, mientras que los afroecuatorianos alcanzan el $3.33 \%$ y los indígenas del $2.92 \%$.

Este fenómeno de preferencia y aceptación racial donde los blancos salen victoriosos explica no sólo la realidad de la discriminación y la dominación racial en un país que con ello se niega a sí mismo, sino que además es el producto de una vieja estrategia de poder basada en la exclusión racial y en la diferenciación de castas, la cual, desde épocas de la colonia, fue establecida por una clase hegemónica y minoritaria que ha concentrado los privilegios y las garantías de la supremacía racial.

En el Ecuador, el proyecto de construcción de la identidad nacional al menos en algunos medios de comunicación muestra signos de estructurarse erróneamente a base de la apariencia física y del color de la piel, donde la imagen publicitaria del blanco se impone de manera emblemática, no mostrando lo que realmente se es, sino lo que en su conjunto se quisiera ser.

Los privilegios raciales que alimentan el imaginario identitario de los ecuatorianos y que terminan siendo un prerrequisito para la aceptación social son estimulados por los medios de comunicación, quienes presentan imágenes "blancasçomo el biotipo ideal y cuyo rasgo fundamental es el que termina orientando a una masa consumidora. En cambio, cuando hace alusiones a la presencia afroecua- 
toriana, muchas veces la televisión recurre a situaciones ambiguas, como lo demuestra el comercial de un detergente que asocia al color blanco del producto con la piel "negra"de una mujer afro, la cual es relacionada con el trabajo doméstico y de lavandería. O como lo caricaturizaba uno de los programas más vistos en el país, la comedia "Vivos", que mostraba a los afros en un papel de ladrones o de clase social baja.

Los medios de comunicación en nuestro país no siempre cumplen con la finalidad en la que son requeridos, como integrar a los colectivos sociales. Así se potenciará el racismo como eje central de nuestro discurso.

El Estado Ecuatoriano desde el 2008 cuenta con una nueva Constitución en la cual se precisan elementos de mucha importancia para el desarrollo del derecho a la comunicación libre, intercultural, incluyente, diversa y participativa en todos los ámbitos de la interacción social. A continuación, se citan algunos artículos de la Constitución del Ecuador 2008:

El artículo 19 pone de manifiesto la necesidad de regular los contenidos de los medios de comunicación en su programación y publicidad. Establece que: La ley regulará la prevalencia de contenidos con fines informativos, educativos y culturales en la programación de los medios de comunicación, y fomentará la creación de espacios para la difusión de la producción nacional independiente. Se prohíbe la emisión de publicidad que induzca a la violencia, la discriminación, el racismo, la toxicomanía, el sexismo, la intolerancia religiosa o política y toda aquella que atente contra los derechos (Nacional, 2008).

María Aracely Guerrero Cedeño es la autora de la tesis "Presentadores del noticiero de la televisión pública: ¿son imágenes de plurinacionalidad?", un trabajo realizado en la Pontificia Universidad Católica del Ecuador Facultad de Comunicación, Lingüística y Literatura Escuela de Comunicación.

Guerrero, tiene como objetivo "analizar si la imagen de los presentadores del noticiero estelar de la Televisión Pública, ECTV, corresponde a una identidad plurinacional o responde a una generalidad que busca atraer adeptosconsumidores basándose en estereotipos, generando así una visión limitada de la diversidad cultural ecuatoriana, la participación y la profesionalidad periodística" (Cedeño y Aracely, 2015).

El propio trabajo cita al profesor colombiano Omar Rincón y al profesor ecuatoriano Mauricio Estrella, autores del libro "Televisión: pantalla o identidad" (Rincón y Estrella, 2001). Ambos indican que los presentadores de los noticieros son la representación de un espejo social, por tanto, son la primera relación real con el telespectador al reflejar una realidad nacional y cultural.

Se considera importante el análisis de la interculturalidad ya que muestra una visión limitada de la diversidad cultural ecuatoriana y nos hace una reflexión sobre el papel que juegan los medios de comunicación en la sociedad de nuestro país, donde debería prevalecer la tradición y los orígenes culturales.

A menudo los medios de comunicación insisten en las diferencias culturales. Presentan las costumbres y tradiciones de poblaciones rurales o ancestrales como situaciones raras y sorprendentes, de esa manera fomentan hostilidad, se impulsa el racismo especialmente hacia las personas de raza negra y minoría como los indígenas.

Son muchas de las formas y las prácticas del racismo en el Ecuador. El Instituto Ecuatoriano de Estadísticas y Censos hizo una encuesta que nos ayuda a entender la magnitud de este problema. Dicha encuesta fue publicada por Diario El Universo, el 22 de marzo del 2005 (Universo, 2005).

A menudo se puede observar en películas y series infantiles, así como en aquellas cuyo contenido simbólico está dirigido para público adulto, que las representaciones se dividen en dos polos bien marcados: los buenos, aquellos héroes caracterizados como patriotas, blancos, rubios, de ojos claros, que luchan hasta el final por la justicia y se quedan con la mujer hermosa y; los malos, aquellos cuyos rostros oscilan entre los rasgos étnicos como indios, africanos, árabes, rusos u otros, quienes tienen la finalidad de desestabilizar al mundo.

En Ecuador existen representantes de diferentes medios que han luchado contra estos estereotipos culturales, quienes indican no ha sido fácil obtener un puesto en la televisión nacional.

Richard Barker, Luis Aguirre, Ludy Caicedo, Mayra Montaño entre otros, son afrodescendientes que han destacado su participación en las producciones nacionales y en la actualidad son reconocidos por todo el país

A partir de la nueva reforma de la Constitución del Ecuador en el 2008 se ha promovido la regulación de la programación de los medios de comunicación, desde un enfoque de derechos humanos y de la naturaleza.

Por esta razón en la actualidad se han podido observar ligeros cambios en la parrilla de programación de algunos canales, como por ejemplo en RTS (Canal 4 de Guayaquil, fue el pionero en contar con un noticiero en quichua llamado Kichuaipi que se transmitía hasta hace unos años a las 5:45 am.

Actualmente, es el canal del Estado, EcuadorTv, el que incluye un noticiero en este idioma que se llama Villaykuna.

Los medios de comunicación juegan un papel fundamental en el tratamiento de asuntos étnicos, y lo hacen promoviendo tanto los prejuicios como, indirectamente, las prácticas sociales discriminatorias, basadas en las creencias negativas que se tienen sobre esos "otros".

Eduardo Encalada, Fernando García y Kristine Ivarsdotter (1999) son los autores de la investigación "La participación de los pueblos indígenas y negros en el desarrollo del Ecuador".

En ese artículo señalan que la identidad de los pueblos indígenas de la Sierra tiene relación con algunos factores 
propios de la región: es la zona con mayor concentración de población indígena, ha estado sujeta a un despojo de la tierra propiedad de las comunidades y a la sobre explotación de la mano de obra por parte de los grandes y medianos productores desde la época colonial, ha sufrido procesos de migración temporal y definitiva de su población hacia otras regiones del país en búsqueda de tierra y trabajo, ha sido área de intervención preferida de los principales proyectos de desarrollo rural auspiciados por el Estado desde la década de los 50, ha enfrentado divisiones internas por la presencia de sectas religiosas evangélicas en los últimos 50 años y ha generado las principales formas de organización política de la población en el transcurso del tiempo (Encalada, García, \& Ivarsdotter, 1999) .

Por su parte, el pueblo negro asentado principalmente en la Costa norte y en la Sierra norte muestra rasgos específicos que forman parte de su identidad: la presencia de un grupo de población minoritario en relación con los otros grupos poblacionales, la dedicación a las actividades de extracción de recursos naturales, agrícolas y de comercio como forma de articulación a la sociedad nacional, la ausencia de delimitación de sus territorios a pesar de ser pobladores ancestrales, la ausencia de la presencia del Estado en la construcción y acceso de servicios básicos, la migración definitiva de buena parte de la población hacia las grandes ciudades en búsqueda de fuentes de trabajo y una baja participación política como grupo étnico en el contexto nacional. En el momento actual de desarrollo que vive el Ecuador los diferentes pueblos indígenas y negros se encuentran, en mayor o menor grado, articulados de alguna manera a la sociedad nacional. Es decir, ninguno de ellos, a excepción tal vez del pequeño grupo de los Tagaeri perteneciente al pueblo Huaorani de la Amazonía, puede sobrevivir en forma autosuficiente, sin necesitar de alguna forma de relación con los demás grupos sociales y culturales que forman parte del país.

Con la llegada de la Ley Orgánica de Comunicación, en el Ecuador comenzó a vivirse una nueva era en la información pública y de interés general. Esta ley contempla la aparición jurídica de la Superintendencia de la Información y Comunicación, que es un organismo técnico de vigilancia, auditoría, intervención y control en el ámbito administrativo del ejercicio de los derechos a la comunicación, establecidos constitucionalmente.

La Supercom (abreviatura de este organismo) es la encargada de sancionar a los medios que difundan contenidos o imágenes discriminatorias. Por ello, desde su creación ha impuesto varias sanciones correspondientes a este tema.

\section{Metodología}

Esta investigación es un estudio explorativo donde se ha aplicado la técnica de la encuesta a una muestra no probabilística por conveniencia de 15 personas afrodescendientes y 15 indígenas, todos ellos habitantes de la ciudad de Guayaquil, aunque hayan nacido en otras provincias.
Ellos fueron encuestados con el fin de saber si perciben que en la televisión ecuatoriana discriminan a las personas de sus razas. Además, se les preguntó si la Ley Orgánica de Comunicación ha contribuido para que esta discriminación vaya disminuyendo progresivamente. Sus respuestas son valiosas aportaciones en la lucha contra la marginación social que sufren indígenas y afrodescendientes en el Ecuador.

\section{Análisis de resultados}

Este análisis presenta los resultados de la encuesta a 15 afrodescendientes y 15 indígenas la cual pretendió medir algunas percepciones acerca de la discriminación racial.

\subsection{Preguntas dirigidas a 15 personas Afrodescendientes}

1) ¿Cree usted que la palabra Negro en televisión es discriminatoria?



Figura 1: Palabra "negro" discriminatoria en Tv Elaborado: Karla Moncayo e Ingrid Estrella

Un $40 \%$ dijo que sí, un $60 \%$ respondió que no. Esto contradice lo actuado por la Supercom en uno de los más complejos casos donde se sancionó al medio Ecuavisa, luego de que el presentador del programa "Contacto Directo", Alfredo Pinoargote, usara la palabra negro para referirse a los afrodescendientes. Una exasambleísta presentó la denuncia y Supercom dictaminó que la palabra negro es peyorativa, por lo cual sancionó al medio (Telégrafo, 2014).

2) ¿Cree usted que en la televisión ecuatoriana discriminan a los periodistas de raza negra?

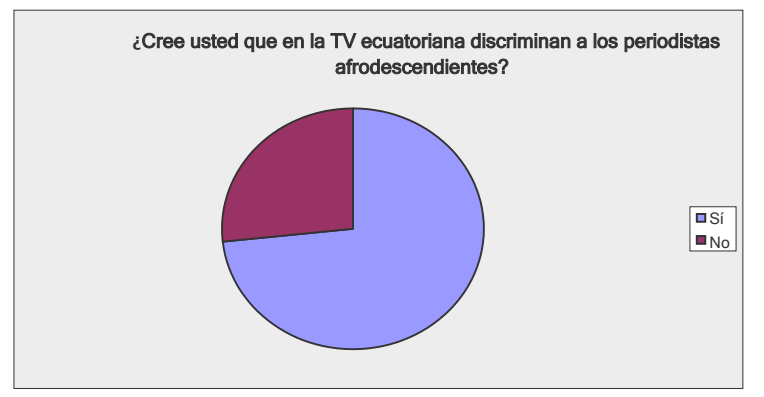

Figura 2: Tv. ecuatoriana discrimina a periodistas afrodescendientes

Elaborado: Karla Moncayo e Ingrid Estrella 
Un $73.3 \%$ dijo que sí, un $26.7 \%$ dijo que no, lo cual evidencia que aún los afroecuatorianos se sienten relegados, marginados en la televisión ecuatoriana, donde al momento no se puede visualizar la presencia de periodistas de raza negra. En los registros de años anteriores solo constan dos mujeres afrodescendientes que trabajaron en noticieros, Ludy Caicedo y Mayra Montaño, esta última es conocida como "La Bombón”.

3) ¿Considera usted que ahora hay más discriminación en la televisión ecuatoriana contra afrodescendientes que antes de que se apruebe la Ley de Comunicación?



Figura 3: Tv. ecuatoriana discriminatoria antes y después de que se apruebe la LOC

Elaborado: Karla Moncayo e Ingrid Estrella

Un $6,7 \%$ de los encuestados dijo que sí, un $93.3 \%$ respondió que no. Esto revela que los afrodescendientes valoran los cambios que están provocando en la televisión ecuatoriana la Ley Orgánica de Comunicación, respecto a la discriminación racial. Esto, considerando que la LOC en su artículo 62, prohíbe los contenidos que puedan ser considerados discriminatorios.

Está prohibida la difusión a través de todo medio de comunicación social de contenidos discriminatorios que tenga por objeto o resultado menoscabar o anular el reconocimiento, goce o ejercicio de los derechos humanos reconocidos en la Constitución y en los instrumentos internacionales.

Se prohíbe también la difusión de mensajes a través de los medios de comunicación que constituyan apología de la discriminación e incitación a la realización de prácticas o actos violentos basados en algún tipo de mensaje discriminatorio (Nacional, 2013).

\subsubsection{Preguntas dirigidas a 15 personas indígenas}

1) ¿Cree usted que la palabra "indio" en televisión es discriminatoria?

De los 15 encuestados, un $60 \%$ dijo sí y un $40 \%$ dijo no. Es decir, la mayoría siente que los mestizos y blancos utilizan el apelativo "indio" para dirigirse a ellos con menosprecio, de manera despectiva. (Figura 4)



Figura 4: Palabra de indios en tv. es discriminatoria Elaborado: Karla Moncayo e Ingrid Estrella

2) ¿Cree usted que en la televisión ecuatoriana discriminan a los periodistas de raza indígena?



Figura 5: Tv. ecuatoriana discrimina a periodistas indígenas Elaborado: Karla Moncayo e Ingrid Estrella

La totalidad los encuestados dijo que sí (100\%). Esto demuestra que en mayor medida que los afrodescendientes, los indígenas se sienten marginados y excluidos por las televisoras del Ecuador, donde hasta el momento no se registran periodistas de las etnias ancestrales en ningún noticiero. Tan solo han contratado indígenas para que realicen labores de traductores del idioma español al quichua.

3) ¿Considera usted que ahora hay más discriminación en la televisión ecuatoriana contra los indígenas que antes de que se apruebe la Ley de Comunicación?

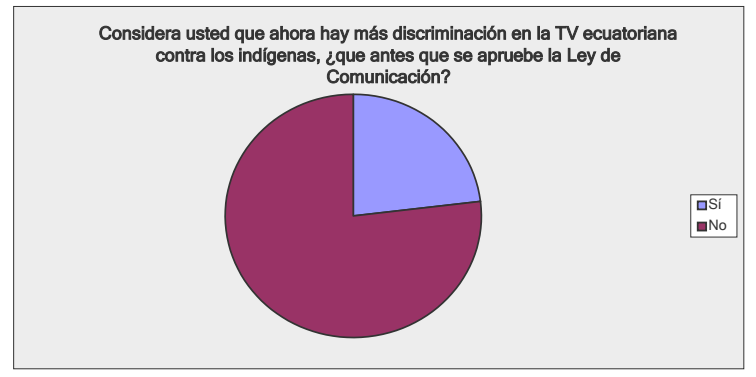

Figura 6: Tv. ecuatoriana discriminatoria antes y después de que se apruebe la LOC

Elaborado: Karla Moncayo e Ingrid Estrella

El $23.1 \%$ dijo que sí y un $76.9 \%$ dijo que no. Esto quiere decir que, en la actualidad, en los canales de televisión y gracias a la Ley Orgánica de Comunicación, ellos sienten que el nivel de discriminación hacia los indígenas ha disminuido. 


\section{Conclusiones y recomendaciones}

Los antecedentes teóricos y epistemológicos aquí expuestos demuestran que el racismo contra las personas afrodescendientes e indígenas siempre ha estado presente en la sociedad ecuatoriana. Los representantes de estas razas no han tenido un trato justo o de igualdad a lo largo de la historia y muchas veces, la discriminación contra ellos fue una ideología planteada por el poder, para mantenerlos sometidos. Los canales de televisión han sido -en partecómplices de este status quo, por cuanto hicieron más grande la brecha al transmitir programadas donde sacaban a relucir los estereotipos contra indígenas y afros. Pero, sobre todo, por no dar cabida en sus estaciones televisivas a personas de estas razas, para que se integren en sus equipos periodísticos o de producción.

Así lo perciben los indígenas y afrodescendientes encuestados en esta investigación. Ellos aún sienten que la televisión ecuatoriana los discrimina por su color de piel, forma de hablar, vestirse y cultura en general.

Por ello, es importante manifestar que todos somos iguales y que todos tenemos derecho a lograr sueños y que estos no sean truncados por el color de la piel, por la forma de vestir o por cuestión de etnia.

Que ser afro o indígena no sea impedimento para llegar a ser un personaje reconocido en la televisión, no por ser blanco de mofas o burlas en ciertos programas cómicos, sino por ser un ícono representativo en el trabajo periodístico.

$\mathrm{Al}$ presentarles la percepción de muchas personas que han sido discriminadas, se quiere crear conciencia de este mal. No en vano, los encuestados abrieron su corazón para mostrar cuánto han tenido que sufrir día tras día, años tras años.

Se considera que los resultados de este estudio son de gran aporte para la industria televisiva y brindan información importante a la hora que tomar decisiones, sobre todo en cómo incluir en sus programas a profesionales de los sectores de la sociedad que aún no son tomados en cuenta y de esta manera fomentar la inclusión y la diversidad en los medios.

Este trabajo concluye con una frase del heroico e inolvidable defensor de los derechos de los afroamericanos, Martin Luther King Jr.: "Hemos aprendido a volar como los pájaros, a nadar como los peces, pero no hemos aprendido el sencillo arte de vivir como hermanos".

\section{Referencias Bibliográficas}

Cedeño, G., y Aracely, M. (2015). Presentadores del noticiero de la televisión pública: ¿son imágenes de plurinacionalidad? Pontificia Universidad Católica del Ecuador. Descargado de http://repositorio.puce.edu.ec: $80 / \mathrm{xmlui} / \mathrm{handle/22000/9669}$

Nacional, A. (2008). Constitución del ecuador. Descargado de http://www.presidencia.gob.ec/ wp-content/uploads/downloads/2013/

$08 /$ LeyDeComunicacion-espaniol.pdf

Nacional, A. (2013). Ley orgánica de comunicación. Descargado de http://www.presidencia -gob.ec/wp-content/uploads/ downloads/2013/08/LeyDeComunicacion -espaniol.pdf

ONU. (1948). La declaración universal de derechos humanos. Descargado 18 de octubre de 2017, de http://www.un.org/es/universal -declaration-human-rights/

Rincón, O., y Estrella, M. (2001). Televisión: pantalla e identidad. Friedrich Ebert Stiftung.

Telégrafo, E. (2014). Sanción a ecuavisa por comentarios de alfredo pinoargote. , 19. Descargado de http: // www.eltelegrafo.com.ec/noticias/ politica/2/sancion-a-ecuavisa-por -comentarios-de-alfredo-pinoargote (19 de febrero de 2018)

Universo, E. (2005). En ecuador domina el racismo. Descargado 19 de febrero de 2018, de https:// www.eluniverso.com/2005/03/22/0001/ 12/836476D 6648E41DC9DDE7439F4AB8C6A .html

Recibido: 19 de febrero de 2018

Aceptado: 13 de mayo de 2020 